\title{
Sensory Profiles and Lactic Acid Bacteria Density of Tape Ketan and Tape Singkong in Bogor
}

\author{
Uswatun Hasanah ${ }^{1,2}$, Haqqifizta Ratihwulan ${ }^{1}$, Lilis Nuraida ${ }^{1,2}$ \\ ${ }^{1}$ Department of Food Science and Technology, Faculty of Agricultural Engineering and Technology, \\ Bogor Agricultural University, Kampus IPB Dramaga PO Box 220 Bogor 16002, Indonesia \\ ${ }^{2}$ Southeast Asian Food and Agricultural Science and Technology (SEAFAST) Center, LPPM IPB, \\ Jl. Puspa No. 1 Kampus IPB Dramaga Bogor, Indonesia \\ *Email: uswatun.hasanah@ipb.ac.id
}

Submission: 29 November 2017; Acceptance: July 312018

\begin{abstract}
Tape ketan (fermented glutinous rice) and tape singkong (fermented cassava) are traditional Indonesian foods produced by fermenting carbohydrate sources using ragi as starter culture. Those products known to contain high number of lactic acid bacteria (LAB). The purpose of the study was to evaluate the sensory characteristics of tape ketan and tape singkong from different household industry in Bogor, to identify the sensory profile, and to evaluate the correlation between $\mathrm{LAB}$ density and sensory attribute. The research was started by survey to household tape industries, followed by sensory analysis of rating hedonic and Quantitative Descriptive Analysis (QDA), and LAB analysis. Data analysis of rating hedonic was done by ANOVA and post-hoc Duncan test, while data analysis of QDA was done by Principle Component Analysis (PCA). Samples of tape ketan were taken from two different home industries (BK and LK), while samples of tape singkong were taken from four different home industries (CT, NG, $\mathrm{SH}, \mathrm{TS}$ ). Hedonic rating test showed that the most preferred sample overall was tape ketan BK and tape singkong CT. QDA results showed that tape ketan BK was characterized by its sweetness, rice-like aroma, rice-like taste, and texture, while tape ketan LK was characterized by alcoholic aroma, alcoholic taste, sourness, and color. Tape singkong NG were characterized by sour aroma, alcoholic aroma, alcoholic taste, and color. Specific characteristic of tape singkong CT was bitterness and bitter aftertaste, SH was sweetness, and TS was texture. LAB of tape ketan BK (8.5 log cfu/g) was higher than LK (7.9 log cfu/g). Tape singkong with highest density of LAB was TS (8.1 log cfu/g), followed by CT (7.2 log cfu/g), NG (7.0 log cfu/g), and SH (6.5 log cfu/g). There was no correlation between the density of LAB and descriptive score of sourness, alcoholic taste, and sweetness.
\end{abstract}

Keywords: QDA; sensory profile; tape ketan; tape singkong; taste

\section{INTRODUCTION}

Fermentation is one of the efforts to prolong storage life of food with high water content and nutrition so that it does not deteriorate easily, especially in tropical countries like Indonesia (Nuraida, 2015). Swain et al. (2014) reported that fermentation is capable of lowering anti-nutrition compounds such as oxalate and phytic acid, and to give desired taste, aroma, and flavor. Furthermore, fermentation can also change rheological, chemical and sensory characteristics of food, such as sourdough, carrot puree, and tempeh (Falade et al.,
2014; Juvonen et al., 2015; Utami et al., 2015). Tape is a traditional food produced through a fermentation process on carbohydrate or starchy food (Barus and Wijaya, 2011). Tape is generally produced traditionally, therefore, there is no established standard either for its production process or its products (Pawiroharsono, 2007). There are two types of tape produced commercially in Indonesia, cassava tape and glutinous rice tape. The quality of tape depends on the quality of basic material, preparation method, and microbial content (Barus et al., 2013). The starter used to produce tape is called yeast. 
Mold, yeast, and bacteria have their own roles in developing the characteristics and flavor of tape. The mold which takes the role in tape fermentation is Amylomyces rouxii, while the yeasts commonly found in tape are Hyphopichia burtonii (Endomycopsis burtonii), Saccharomycopsis fibuligera (Endomycopsis fibuligera), and Candida beverwijkiae (Candida pellicullosa)(Nuraida and Owens, 2014). Law et al. (2011) also stated that $A$. rouxii and $C$. pelliculosa are dominant microorganisms in tape, followed by Saccharomyces cerevisiae and Hansenula anomala. In the fermentation process, $A$. rouxii dan $C$. berverwijkiae hydrolize starch into sugar. There are two types of $A$. rouxii, one type produces lactic acid and ethanol, and the other type produces only ethanol. S. cerevisae is known to have the ability to ferment sugar while Wickerhamomyces anomalus and C. berverwijkiae contribute in developing ester aroma in tape (Nuraida and Owens, 2014).

Other than mold and yeast, microorganisms that are also found in tape are bacteria such as lactic acid bacteria ( $L A B$ ) and acetic acid bacteria (AAB). The $L A B$ found in tape are Weisella spp, Pediococcus pentosaceus, Enterococcus spp (Sujaya et al., 2010), while the AAB type found are Acetobacter. The other bacteria found in tape are Bacillus spp. (Barus et al., 2013). The LAB in commercial tape in Indonesia are between $10^{6}-10^{7}$ $\mathrm{cfu} / \mathrm{g}$, while $A A B$ are between $10^{5}-10^{7} \mathrm{cfu} / \mathrm{g}$. The lactic acid in tape comes from glucose anaerobic fermentation by amylolytic microorganisms such as $A$. rouxii mold and/or the presence of LAB (Saito et al., 2004; Nuraida and Owens, 2014).

$L A B$ are microorganism group commonly used in fermented foods. There are two types of $L A B$ based on the fermentation types, homo-fermentative and heterofermentative. Homo-fermentative $L A B$ ferment $1 \mathrm{~mol}$ of glucose into $2 \mathrm{~mol}$ of lactic acid and $2 \mathrm{~mol}$ ATP, while hetero-fermentative LAB ferment $1 \mathrm{~mol}$ of glucose into $1 \mathrm{~mol}$ of lactic acid, ethanol/acetic acid, $\mathrm{CO}_{2}$, and 1 mol ATP (Salminen et al., 2004). LAB plays a role in producing high value metabolites which are involved in developing flavor and texture (Kumar and Murugalatha, 2012; Steele et al., 2013). With these characteristics, $L A B$ presence probably influences tape flavor.

Although there are a lot of researches on fermentation products investigates the only few correlation between sensory profile and bacteria density, especially $L A B$. This research aims to determine the sensory profile and $L A B$ density of rice tape and cassava tape in several household industries in Bogor, identify the specific flavor, and the correlation between lactic acid bacteria density and flavor. This research is beneficial in providing information and data about attributes which characterize rice tape and cassava tape. This research also provides data about $L A B$ density which can explain the roles of $L A B$ in sensory attributes in rice tape and cassava tape.

\section{RESEARCH METHOD}

\section{Materials}

The main materials in this research are cassava tape and rice tape taken from several household industries in Bogor. The tape samples used are: cassava tape brands CT (Cibeuteung), NG (Nanggerang), SH (Sukahati), and TS (Tanah Sareal), and rice tape brands LK (Leuweung Kolot) and BK (Bantar Kambing). The materials for biological analysis are media de Man Ragosa Sharpe Agar (MRSA) (Oxoid, UK), de Man Ragosa Sharpe Broth (MRSB) (Oxoid, UK), Nutrient Agar (NA) (Oxoid, UK) D-glucose, skimmed milk, yeast extract, $\mathrm{NaCl} 10 \%$ (Merck, DE), tartaric acid, sodium azide, sterile glycerol 20, aquades, 95\% alcohol, Gram coloring agent, and $\mathrm{pH} 4$ and 7 buffers for $\mathrm{pH}$ calibration. The materials for sensory analysis are sucrose (food grade, Merck, DE), citric acid (food grade, Aquatic, ID), caffeine (food grade, Merck, DE), acetic acid (table vinegar DIXI, ID), MSG (food grade, Merck, DE), NaCl (food grade, Merck, DE), bottled water, peppermint, vanilla extract, apple flavored You C-1000 vitamin drink (PT Djojonegoro C-1000, ID), sugar, red rice, and Cilembu sweet potatoes.

\section{Tools}

The tools used in this research are micropipette, stomacher (Bagmixer Interscience, FR), pH-meter (Eutech Instrument, SG), vortex (Vortex-Genie 2, US), incubator, centrifuge (Beckman J2-21, US), autoclave (ALP MC-40, JP), water bath, burette, glass tools for microbiological analysis, and tools for sensory analysis.

\section{Household Tape Industry Survey}

Survey was conducted on two household industries which produce rice tape and four household industries which produce cassava tape in Bogor. This stage was performed by observing production process differences in each industry. The information collected from the tape household industries include process, basic materials, and yeast.

\section{Sensory Analysis: Hedonic Rating Test}

An affective test in the form of hedonic rating refers to Meilgaard et al. (2007) was conducted to determine consumers' preference towards rice tape and cassava tape. The test involved 70 IPB students, aged between $20-23$ years, as untrained panelists. Samples were served with three-digit codes and were presented 
one after another. The hedonic scale used was $1-7$, in which 1 = very much disliked; 2 = disliked; 3 = slightly disliked; $4=$ neutral; $5=$ slightly liked; $6=$ liked; 7 $=$ very much liked. The attributes tested were taste, aroma texture, and products' overall acceptance. The data of hedonic rating test results were processed using one-way ANOVA and Duncan's further test.

\section{Sensory Analysis: Quantitative Descriptive Analysis (QDA)}

Quantitative Descriptive Analysis (QDA) was conducted to determine rice tape and cassava tape sensory profiles. The panelists involved were 15 students of Food Science and Technology Department, Institut Pertanian Bogor, who have undergone a process of selection and training. Panelist selection referred to ISO 8586 (2012), which included pre-screening and acuity test. The pre-screening was in the form of questionnaire completion to determine the panelist candidates' health history, food habit, and possibilities of allergies towards certain kinds of food. Acuity test was conducted using two methods, (a) Ishihara test to determine the panelist candidate's ability to see colors, and (b) basic taste and aroma identification as a general method to assess the taste and smell senses. The concentration of five basic taste compounds refers to ISO 8586 (2012). The passing requirements that must be fulfilled by panelist candidates are verified as not color blind using the Ishihara test; $100 \%$ correct answers for basic taste identification test; and $80 \%$ correct answers for basic aroma identification test. Panelists who passed the selection stage were allowed to proceed to the next stage, training.

The training stage aims to train panelists' sensitivity and assessment consistence to become a trained panelist. Panelist training consists of a triangular test; FGD; test reference determination; and scale using training. A triangular test is conducted to determine panelists' ability to differentiate samples with low concentration differences. Samples were in the form of pure sucrose solutions with $6 \%$ and $7 \%$ concentrations. The test was conducted in three series with samples served randomly. The selected panelists' ability to differentiate concentrations has fulfilled the requirement, that is, minimum $50 \%$ correct answers.

Focus group discussion (FGD) was conducted to equate perceptions and terminologies of tape flavors among panelists. FGD also produced sensory attributes contained in rice tape and cassava tape. The attributes assessed in rice tape were alcohol aroma; rice aroma; sour taste; alcohol taste; sweet taste; rice taste; texture; and color, whereas attributes assessed in cassava tape were alcohol aroma; sour aroma; alcohol taste; sour taste; sweet taste; bitter taste; bitter aftertaste; and texture. Panelists also determined a reference for each attribute and its concentration value, which is used in QDA test. The reference value was determined using Steven's Law (Meilgaard et al., 2007). Panelists were trained to give intensity assessment using line graphs.

The QDA test was performed in four-time repetitions for each of the rice tape and cassava tape samples and attributes. Panelists conducted tests in individual booths in order to avoid bias. In each sample change, panelists neutralized their taste buds by drinking mineral water and neutralized their smell by resting for 10 seconds. Intensity assessment was conducted using a $10-\mathrm{cm}$ structured scale, the scale remarks were 0 (very weak) at the beginning of the scale and 100 (very strong) and the end of the scale. The average descriptive data scores were visualized into a spider web chart and were processed using Principal Component Analysis (PCA) to produce a Biplot chart.

\section{LAB Total Analysis}

Microbiological analysis in the form of total $L A B$ (BAM, 2001) was conducted on rice tape and cassava tape. A $25 \mathrm{~g}$ sample was weighed using sterile plastic

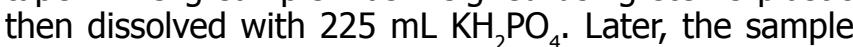
mixture was diluted in series. A $1-\mathrm{mL}$ sample was retrieved using a pippete into a sterile petri dish (duplo) and Man Rogosa and Sharpe Agar (MRSA) added with $0.02 \%$ sodium azide was poured. The dish was incubated upside down at a temperature of $37^{\circ} \mathrm{C}$ for 48 hours. Microbe count was performed using a standard plate count method.

\section{RESULT AND DISCUSSION}

\section{Rice Tape and Cassava Tape Production Method}

The rice tape sample were taken from household industries BK and LK. BK and LK's process used a mix between black glutinous rice and white glutinous rice with $1: 1$ ratio. The flow of rice tape production included soaking the basic ingredient for 24 hours; two times washing and steaming; cooling; adding yeast; incubation; and packing. The difference lied in the type of yeast used. BK rice tape uses Ragi Mutiara brand yeast, whereas LK rice tape uses Ragi Leuwiliang brand yeast. The amount of yeast added was between 0.1 $-0.3 \%$ of the rice tape produced. LK rice tape was incubated in plastic packing boxes and was added with cariang leaf.

Cassava tape from household industries CT, NG, $\mathrm{SH}$, and TS was produced with similar general stages, 
including peeling, scraping, washing, boiling, cooling, adding yeast, packing into baskets layered with banana leaves, and incubation. The difference between one household industry and the other lied in the age of cassava basic materials and the yeast used. The cassava used by CT, NG, and SH is 7 months old, whereas the cassava used by TS is 10 months old. The four household industries used different types of yeast for fermentation. The amount of yeast added was between $0.1-0.4 \%$ of the cassava produced.

\section{Evaluation of Rice Tape and Cassava Tape Hedonic Sensory Rating}

Hedonic rating evaluation was conducted to determine untrained panelists' preference on various sensory attributes in LK and BK rice tape, and also in CT, NG, SH and TS cassava tape. The rice tape and cassava tape hedonic scores are presented in Table 1 below.

Evaluation results in the form of hedonic scores show that BK rice tape is more preferred in terms of taste and texture attributes, whereas LK rice tape is more preferred in terms of color and aroma attributes. Panelists' preference towards aroma and texture attributes is not significantly different between the two rice tape brands, whereas panelists' preference towards taste and color is significantly different between the two brands of rice tape at a significance level of $5 \%$. Overall, BK rice tape was more preferred than LK rice tape, the score for BK was 4.88 (neutral towards slightly liked) and the score for LK was 3.94 (slightly disliked towards neutral). Panelists' overall preference scores for BK rice tape and LK rice tape differ significantly at a significance level of $5 \%$. This shows that taste attribute is more decisive in determining preference towards rice tape in general.

Panelists gave the preference assessment on CT, NG, SH and TS cassava tape at a range between 3 (slightly disliked) and 5 (slightly liked). Based on

Table 1. Rice tape and cassava tape hedonic scores

\begin{tabular}{lcccccc}
\hline \multirow{2}{*}{$\begin{array}{l}\text { Sensory } \\
\text { attributes }\end{array}$} & \multicolumn{6}{c}{ Hedonic scores } \\
\cline { 2 - 7 } & \multicolumn{2}{c}{ Rice tape } & \multicolumn{5}{c}{ Cassava tape } \\
\cline { 2 - 7 } & BK & LK & CT & NG & SH & TS \\
\hline Color & $4,82^{\mathrm{a}}$ & $5,47^{\mathrm{b}}$ & $5,58^{\mathrm{c}}$ & $5,18^{\mathrm{b}}$ & $4,93^{\mathrm{b}}$ & $3,97^{\mathrm{a}}$ \\
Aroma & $4,49^{\mathrm{a}}$ & $4,51^{\mathrm{a}}$ & $5,06^{\mathrm{c}}$ & $4,56^{\mathrm{b}}$ & $4,63^{\mathrm{b}}$ & $3,97^{\mathrm{a}}$ \\
Taste & $5,06^{\mathrm{b}}$ & $3,36^{\mathrm{a}}$ & $5,04^{\mathrm{d}}$ & $3,56^{\mathrm{b}}$ & $4,06^{\mathrm{c}}$ & $3,10^{\mathrm{a}}$ \\
Texture & $4,79^{\mathrm{a}}$ & $4,53^{\mathrm{a}}$ & $5,29^{\mathrm{d}}$ & $4,22^{\mathrm{b}}$ & $4,72^{\mathrm{c}}$ & $3,44^{\mathrm{a}}$ \\
Overall & $4,88^{\mathrm{b}}$ & $3,94^{\mathrm{a}}$ & $5,25^{\mathrm{c}}$ & $4,04^{\mathrm{b}}$ & $4,39^{\mathrm{b}}$ & $3,40^{\mathrm{a}}$ \\
\hline
\end{tabular}

*Different letters in each column show significant differences at a $5 \%$ rate. statistics analysis results, it is found that NG and $\mathrm{SH}$ cassava tape do not significantly different in attributes of color, aroma and overall. Panelists' preference score towards taste and texture of $\mathrm{CT}, \mathrm{NG}, \mathrm{SH}$, and TS cassava tape have significant differences with $5 \%$ significance level. Evaluation results show that CT cassava tape earned the highest score for all attributes (color, aroma, taste, texture, and overall), with scores around 5 (slightly liked).

\section{Rice Tape and Cassava Tape Sensory Profiles}

Rice tape and cassava tape sensory profiles are obtained through QDA description test, by processing graphical data in the form of spider webs and PCS. These spider web charts show attribute intensity differences among samples, whereas PCA shows samples' specific characteristics. The spider web chart of rice tape and cassava tape are shown in Figure 1 (a) and (b).

Results of rice tape description test in Figure 1 (a) shows that BK rice tape has higher intensity in almost all attributes compared with LK rice tape. BK rice tape has harder texture, lighter color, and stronger rice taste, sweet taste, rice aroma, and alcohol aroma than LK rice tape, whereas LK rice tape has higher intensity alcohol aroma and sour taste than BK rice tape.

The spider web chart in Figure 1 (b) shows that CT cassava tape has the hardest texture and highest bitter taste and bitter aftertaste intensity compared with the other three samples. NG cassava tape has the lightest color, with the highest sour taste, alcohol taste, sour aroma, and alcohol aroma among the four samples. $\mathrm{SH}$ cassava tape has the highest sweet taste, with the lowest bitter taste and bitter after taste compared with the other three samples.

Other than using spider web charts, the data were also processed using Principal Component Analysis (PCA). PCA can detect diversity from the data obtained; the number of diversity is explained from the biggest to the smallest number of hidden differences (Meilgaard et al., 2007). The descriptive sample data of rice tape and cassava tape are displayed in PCA chart in Figure 2.

Profile description of rice tape is performed based on combined PCA chart between rice tape and cassava tape (Figure $2(a)$ ), because rice tape only consists of two samples and could not processed separately in PCA chart. Figure 2 (a) explains the data diversity in F1 main component of $48.98 \%$ and $\mathrm{F} 2$ main component of $21.42 \%$, with a total cumulative diversity of $70.40 \%$. The results from PCA biplot chart show that BK rice tape is characterized by sweet taste; rice taste; rice aroma; and texture, whereas LK rice pate is characterized by alcohol aroma; alcohol taste; sour taste; and color. 


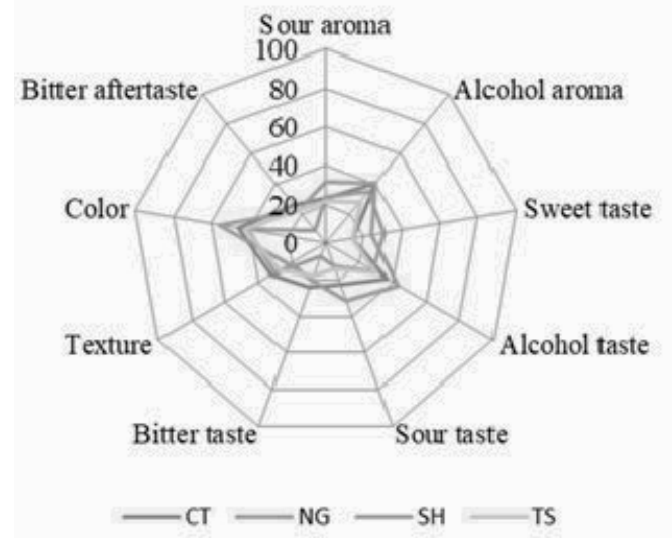

(a)

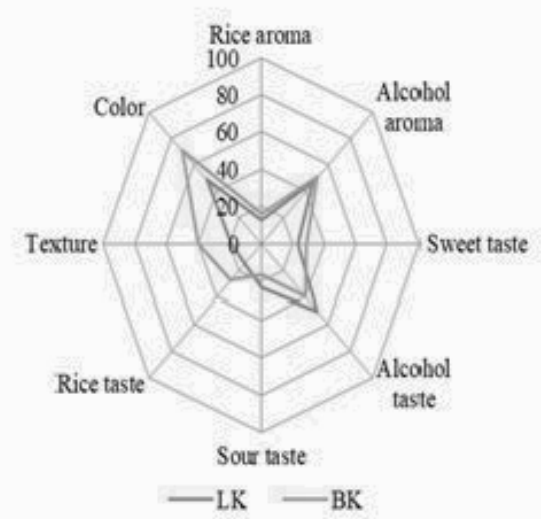

(b)

Figure 1. Spider web chart of rice tape (a) and cassava tape (b). Value 0 - 100: QDA average scores

The profile of cassava tape is obtained from separate PCA chart for the four samples (Figure 1 (b)), because it can explain the diversity of the main component data F1 and F2 (89.36\%) better than the combined PCA chart with rice tape (70.40\%). The comparison among cassava tape shows that the cassava tape with the highest number of characteristics attributes is NG, which is characterized by sour aroma; alcohol aroma; alcohol taste; and color. CT cassava tape is characterized by taste and bitter after taste, $\mathrm{SH}$ cassava tape is characterized by sweet taste, and TS cassava tape is characterized by texture.

The differences in samples' flavors can be linked to the production process. The use of cassava main ingredients which have various ages can influence the flavor of tape produced. The type and levels of starch contained in the main ingredients have an influence on flavor because starch would be hydrolyzed by amylolytic yeast to produce sugar. The sweet taste in tape is influenced by the sugar levels in the tape itself, however, in certain types of tape, there is a strong sour taste developed. This is usually caused by sloppy treatment during the process, such as adding too much yeast; unsuitable condition during the fermentation process; and an extended fermentation duration (Nuraida and Owens, 2014). Besides yeast, LAB also plays a role in the two-stage process in changing starch into glucose through enzymatic saccharification, followed by conversing glucose into lactic acid through lactic fermentation (Reddy et al., 2007).

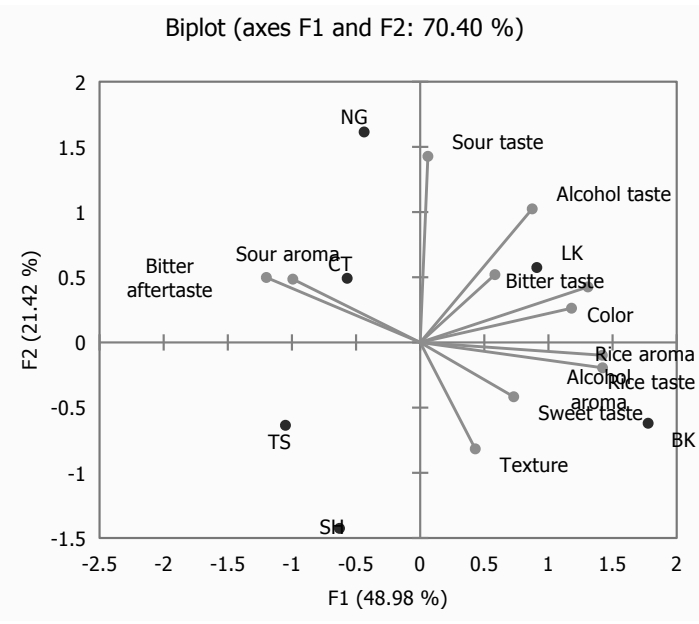

(a)

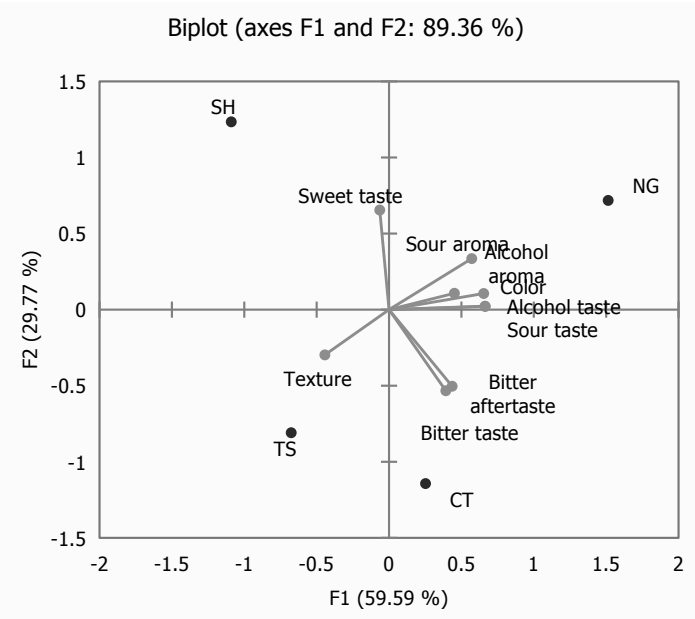

(b)

Figure 2. PCA chart (F1:F2) rice tape and cassava tape (a) and cassava tape (b)

Barus and Wijaya (2011) stated that the use of S. cerevisiae for cassava tape yeast combined with bacteria such as Bacillus subtilis, Lactobacillus plantarum, and Pseudomonas fragi causes a difference in intensity of sweet taste, alcohol aroma, and texture on cassava tape produced. The combination of sour taste from lactic acid, sweet taste from sugar degradation, and alcohol due to $S$. cerevisiae yeast which convert sugar, strongly determines tape flavor so that it has a specific 
characteristic. Nuraida dan Owens (2014) also stated that the culture used in tape yeast produces sensory characteristics such as distinct flavor and aroma of the tape. The production of glucose, lactic acid, and ethanol gives a bit of alcohol taste and sour-sweet taste.

Cronk et al. (1979) stated that $A$. rouxii, with or combined with a different yeast, produces various kinds of alcohol in higher amount, including isobutanol (2-methyl-1-propanol), 2-methyl-1-butanol and isoamyl alcohol (3-methyl-1-butanol). Each of the alcohol type has different sensory characteristics, however, the concentration which can influence the sensory characteristics is not yet known. Even so, it is known that $A$. rouxii with $W$. anomalus (Hansenula anomala) or Wickerhamomyces subpelliculosus (Hansenula subpelliculosa) produce ethyl acetate in large amounts in tape, which is sufficient to give a strong and recognizable alcohol aroma.

The sensory profile of tape can also explain the characteristics of tape preferred by panelists. BK rice tape has specific characteristics of sweet taste; rice taste; rice aroma; and texture. The intensity of each attribute shows that panelists like rice tape which has stronger sweet taste; rice taste; and rice aroma, and harder texture. CT cassava tape has specific characteristics of bitter taste and bitter aftertaste with stronger intensity, and sweet taste with low intensity. Therefore, panelists prefer cassava tape which is not too sweet; with more dominant bitter taste and aftertaste; alcohol taste and aroma; and sour aroma. These results are different from those produced by Barus and Wijaya (2011) which stated that panelists prefer cassava tape that has soft sweet taste and alcohol aroma. The different preference may relate with different eating habits and basic taste preferences of the panelists (Hasanah et al., 2014).

\section{Rice Tape and Cassava Tape Lactic Acid Bacteria Density}

The $L A B$ density in rice tape tends to be higher than cassava tape, as shown by Figure 3 . LAB on BK rice tape is $8.5 \log \mathrm{cfu} / \mathrm{g}$, higher than LK rice tape, which is $7.9 \log \mathrm{cfu} / \mathrm{g}$, but not significantly different at a $5 \%$ significance rate. The cassava tape with the highest LAB density is TS, with $8.1 \mathrm{log} \mathrm{cfu} / \mathrm{g}$; followed by CT with $7.2 \log \mathrm{cfu} / \mathrm{g}$; NG with $7.0 \mathrm{log} \mathrm{cfu} / \mathrm{g}$; and SH with 6.5 log cfu/g. TS cassava tape's LAB density is significantly different from that of $\mathrm{CT}, \mathrm{SH}$, and NG's at a $5 \%$ significance rate.

The results obtained are in accordance to those from Nuraida and Owens (2014) which stated that the $L A B$ found in tape fermentation is between 106-107 $\mathrm{cfu} / \mathrm{g}$. Growol fermentation, a product from processed

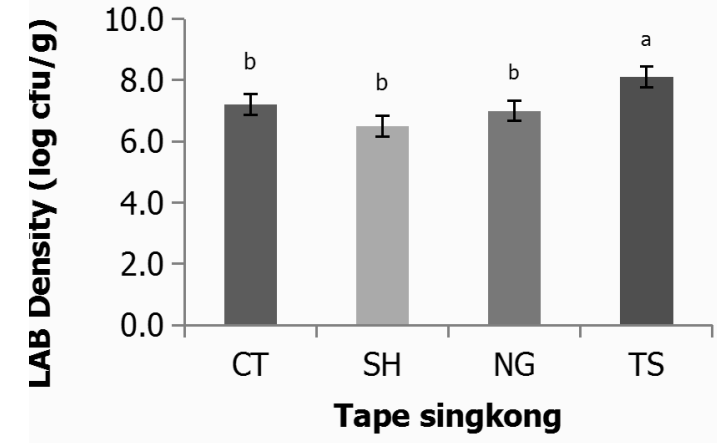

(a)

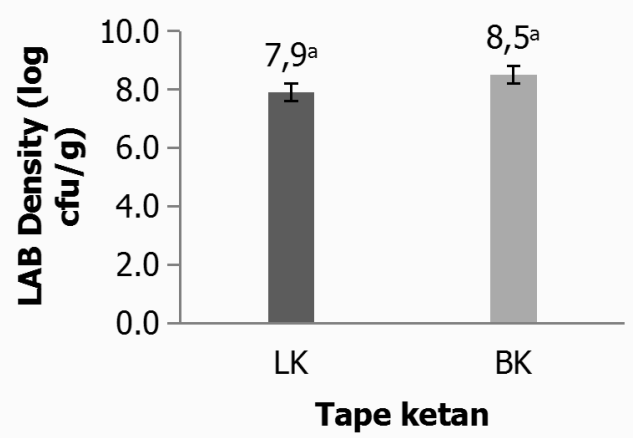

(b)

Figure 3. LAB density in rice tape (a) and cassava tape (b)

* Different letters in each column show significant differences at a $5 \%$ rate

cassava, also involve $\mathrm{LAB}$ with different species (Putri et al., 2011). Almeida et al. (2007) in their study of fermented product with Cauim cassava as the main material, produced by Brazilian Amerindians, stated that the amount of $L A B$ increases from the beginning of fermentation process, and it is the dominant type of microbes throughout the fermentation.

\section{Correlation Between Lactic Acid Bacteria Density and Sensory of Tape}

The descriptive scores in the form of sour taste; sweet taste; and alcohol taste obtained from the sensory analysis is correlated with $L A B$ density in each sample. The correlation results are found in Figure 4.

Analysis results show that the $R^{2}$ value is low, which indicates that there is no correlation between $L A B$ density and sour taste; alcohol taste; and sweet taste. This can be because of the presence of other microorganisms beside $L A B$, which can influence tape flavor. Acetic acid producing bacteria such as Acetobacter spp. can metabolize ethanol into acetic acid and can associate with yeast in alcohol fermentation (Nuraida and Owens, 2014). Barus et al. (2013) reported the presence of 26 Bacillus spp. species contained in tape. Bacillus cereus 


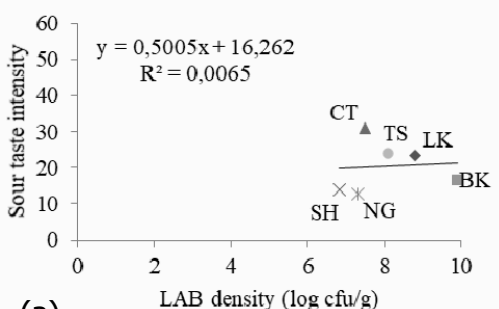

(a)

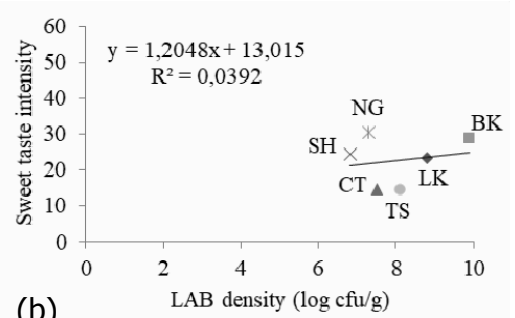

(b)

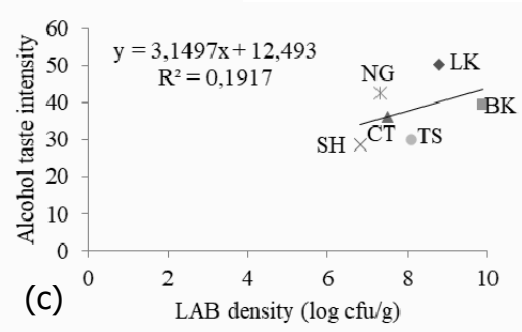

Figure 4. Correlation between $L A B$ density and sour taste intensity (a); sweet taste (b); and alcohol taste (c)

are also identified in Lafun, a traditional West African fermented food with cassava as the main ingredient (Padonou et al., 2009). Joo et al. (2007) in their study of Chungkookjang, a Korean traditional fermented food with soy as the main ingredient, stated that during fermentation, Bacillus spp. produce extracellular enzyme so that they can hydrolyze starch.

Nuraida dan Owens (2014) stated that $A$. rouxii yeast has a type which can produce both lactic acid and ethanol. $S$. cerevisiae yeast is known to have the ability to ferment sugar, whereas $W$. anomalus and $C$. berverwijkiae contribute in the formation of ester aroma in tape. The presence of microorganisms other than LAB with their metabolism results can influence the intensity of sour taste; alcohol taste; and sweet taste in rice tape and cassava tape.

\section{CONCLUSION}

$\mathrm{BK}$ and $\mathrm{LK}$ rice tape are produced with the same stages, and so are CT, NG, SH and TS cassava tape. The differences among these samples lie on the tape yeast used. Overall, the most preferred cassava tape is BK rice tape, which has specific characteristics of sweet taste; rice aroma; rice taste; and texture, and
CT cassava tape with specific characteristics of bitter taste; and bitter aftertaste. BK rice tape has LAB density of $8.5 \mathrm{log} \mathrm{cfu} / \mathrm{g}$, higher than LK with $7.9 \mathrm{log} \mathrm{cfu} / \mathrm{g}$. The cassava tape with the highest LAB density is TS with 8.1 $\log \mathrm{cfu} / \mathrm{g}$, followed by CT with $7.2 \log \mathrm{cfu} / \mathrm{g}$; NG with 7.0 $\log \mathrm{cfu} / \mathrm{g}$; and $\mathrm{SH}$ with $6.5 \mathrm{log} \mathrm{cfu} / \mathrm{g}$. Analysis results show that there is no correlation between LAB density with sensory descriptive scores for sour taste; alcohol taste; and sweet taste. The presence of microorganisms other than $L A B$ with their metabolisms can influence the intensity of sour taste; alcohol taste; and sweet taste in the rice tape and cassava tape.

\section{ACKNOWLEDGEMENT}

We thank the Directorate General of Higher Education, Ministry of Education and Culture, as the research fund provider through the Prominent Research Scheme, based on the Division Mandate year 2016 in the name of Prof. Dr. Ir. Lilis Nuraida, Msc.

\section{BIBLIOGRAPHY}

Almeida, E. G., Rachid, C. C. T. C., \& Schwan, R. F. (2007). Microbial population present in fermented beverage 'cauim' produced by Brazilian Amerindians. International Journal of Food Microbiology 120:146-151. http://doi. org/10.1016/ijfoodmicro.2007.06.020.

BAM. (2001). Aerobic plate count. US FDA Center for Food Safety and Applied Nutrition.

Barus, T., \& Wijaya, L. N. (2011). Mikrobiota dominan dan peranannya dalam cita rasa tape singkong. Biota 16(2):354-361.

Barus, T., Kristani, A., \& Yulandi, A. (2013). Diversity of amylase-producing Bacillus spp. from "tape" (fermented cassava). HAYATI Journal of Biosciences 20(2):94-98. http://doi.org/10.4308/hjb.20.2.94.

Cronk, T. C., Mattick, L. R., Steinkraus, K. H., \& Hackler, L. R. (1979). Production of higher alcohol during Indonesian tape ketan fermentation. Applied and Environmental Microbiology 37(5):892-896.

Falade, A. T., Emmambux, M. N., Buys, E. M., \& Taylor, J. R. N. (2014). Improvement of maize bread quality through modification of dough rheological properties by lactic acid bacteria fermentation. Journal of Cereal Science 60(3): 471-476. https://doi.org/10.1016/j.jcs.2014.08.010.

Hasanah, U., Adawiyah, D. R., \& Nurtama, B. (2014). Preferensi dan ambang deteksi rasa manis dan pahit: pendekatan multikultural dan gender. Jurnal Mutu Pangan 1(1):1-8.

ISO. (2012). ISO 8586 Sensory analysis - General guidelines for the selection, training and monitoring of selected 
assessors and expert sensory assessor. International Standard.

Juvonen, R., Honkapää, K., Maina, N. H., Shi, Q., Viljanen, K., Maaheimo, H., Virkki, L., Tenkanen, M., \& Lantto, R. (2015). The impact of fermentation with exopolysaccharide producing lactic acid bacteria on rheological, chemical and sensory properties of pureed carrots (Daucus carota L.). International Journal of Food Microbiology 207:109-118. https://doi.org/10.1016/j. ijfoodmicro.2015.04.031.

Joo, M., Hur, S., Han, Y., \& Kim, J. (2007). Isolation, identification, and characterization of Bacillus strains from the traditional Korean soybean-fermented food, Chungkookjang. Journal of Applied Biological Chemistry 50(4):202-210.

Kumar, A. M., \& Murugalatha, N. (2012). Isolation of LactoBacillus plantarum from cow milk and screening for the presence of sugar alcohol producing gene. Journal of Microbiology and Antimicrobials 4(1):16-22. http:// doi.org/10.5897/JMA11.083.

Law, S. V., Abu, B. F., Mat, H. D., \& Abdul, H. A. (2011). Mini review: Popular fermented foods and beverages in Southeast Asia. International Food Research Journal 18:475-484.

Meilgaard, C. M., Civille G. V., \& Carr, B. T. (2007). Sensory Evaluation Techniques (4th ed). Boca Raton: CRC Press.

Nuraida, L. (2015). A review: Health promoting lactic acid bacteria in traditional Indonesian fermented foods. Food Science and Human Wellness 4:47-55. http://doi. org/10.1016/j.fshw.2015.06.001.

Nuraida, L., \& Owens, J. D. (2014). Sweet, Sour, Alcoholic Solid Substate Fungal Fermentations. In Owens, J.D. (Ed.), Indigenous Fermented Foods of Southeast Asia (pp. 137-155). Boca Raton: CRC Press.

Padonou, S. W., Nielsen, D. S., Hounhouigan, J. D., Thorsen, L., Nago, M. C., \& Jakobsen, M. (2009). The microbiota of Lafun, an African traditional cassava food product. International Journal of Food Microbiology 133:22-30. http://doi.org/10/1016/j.ijfoodmicro.2009.04.019.
Pawiroharsono, S. (2007). Potensi pengembangan industri dan bioekonomi berbasis makanan fermentasi tradisional. Jurnal Ilmu Kefarmasian Indonesia 5:85-91.

Putri, W. D. W., Mika, M., Nakagawa, Y., Kawasaki, H., Haryadi, Cahyanto, N. M., \& Marseno, D.W. (2011). Differentiation studies of predominant lactic acid bacteria isolated during growol fermentation by using polyphasic taxonomic characterization. African Journal of Biotechnology 10(42):8194-8204.

Reddy, G., Altaf, Md., Naveena, B. J., Venkateshwar, M., \& Kumar, E. V. (2007). Amylolytic bacterial lactic acid fermentation - a review. Biotechnology Advances 26:2234. http://doi.org/10.1016/j.biotechadv.2007.07.004.

Saito, K., Abe, A., Sujaya, I-N., Sone, T., \& Oda, Y. (2004). Comparison of Amylomyces rouxii and Rhizopus oryzae in lactic acid fermentation of potato pulp. Food Science and Technology Research 10(2):224-226. https://doi. org/10.3136/fstr.10.224.

Salminen, S., Wright, A. V., \& Ouwehand, A. (2004). Lactic Acid Bacteria Microbial and Finctional Aspects (3rd ed). New York: Marcel Dekker, Inc.

Steele, J., Broadbent, J., \& Kok, J. (2013). Perspectives on the contribution of lactic acid bacteria to cheese flavor development. Current Opinion in Biotechnology 24(2):135-141. https://doi.org/10.1016/j. copbio.2012.12.001.

Sujaya, I. N., Nocianitri, K. A., \& Asano, K. (2010). Diversity of bacterial flora of Indonesian ragi tape and their dynamics during the tape fermentation as determined by PCRDGGE. International Food Research Journal 17:239-245.

Swain, M. R., Anandharaj, M., Ray, R. C., \& Rani, R. P. (2014). Fermented fruits and vegetables of Asia: a potential source of probiotics. Biotechnology Research International Article ID 250424. http://doi.org/10.1155/2014/250424.

Utami, R., Wijaya, C. H., \& Lioe, H. N. (2015). Taste of watersoluble extracts obtained from over-fermented tempe. International Journal of Food Properties 19(9):20632073. https://doi.org/10.1080/10942912.2015.110450 9. 